\title{
Delayed surgical repair of truncus arteriosus with interrupted aortic arch following bilateral banding of branch pulmonary arteries: a case report
}

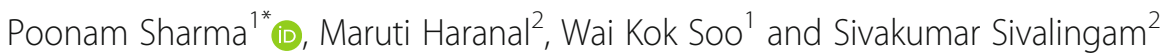

\begin{abstract}
Background: Banding of the bilateral branch pulmonary arteries (PA) has evolved as a palliative method to limit the pulmonary blood flow in various complex congenital heart diseases. Although beneficial in small patients and in those with multiple co-morbidities, the duration of pulmonary artery banding along with growth and status of branch pulmonary arteries following de-banding are of concern in these patients.

Case presentation: We present a case of truncus arteriosus with interrupted aortic arch in whom bilateral PA banding was done in neonatal life. The corrective surgery was delayed by 13 months due to multiple infections and underlying co-morbid conditions. Although the surgery was delayed, the branch pulmonary arteries were of adequate size following the debanding procedure.

Conclusion: Branch PA augmentation may not always be necessary even in delayed corrective surgery following bilateral PA banding.
\end{abstract}

Keywords: Pulmonary artery banding, Biventricular repair, Truncus arteriosus, Interrupted aortic arch, Case report

\section{Background}

Pulmonary artery (PA) banding is an established initial palliation in univentricular hearts to decrease pulmonary blood flow although its use in biventricular heart is debatable in centers opting for primary correction [1]. However, single-stage repair is difficult in neonates particularly those with low birth weight and co-existing morbidities, and also, the possible neurological consequences associated with prolonged cardiopulmonary bypass cannot be ignored. There are few case reports published about the use of bilateral PA banding in biventricular heart as an initial palliation [2]. The timing of the second surgery, growth of the branch PAs and possible distortion of the branch PAs requiring some

\footnotetext{
* Correspondence: medpoonam@gmail.com

${ }^{1}$ Pediatric and Congenital Heart Centre, National Heart Institute, 145, Jalan

Tun Razak, 50400 Kuala Lumpur, Malaysia

Full list of author information is available at the end of the article
}

form of intervention are few issues that remain to be answered [1]. We present a case of truncus arteriosus who underwent definitive corrective surgery after 13 months of bilateral PA banding without distortion of the branch PA. Ethical approval from the institutional review board and informed consent was taken from the parents for publishing the case.

\section{Case presentation}

Term boy was delivered with birth weight of $1.8 \mathrm{~kg}$. Bedside $2 \mathrm{D}$ echocardiography done for an incidental murmur showed truncus arteriosus (TA) type II with interrupted aortic arch (IAA) type B and a large patent ductus arteriosus (PDA) and hence, was started on intravenous prostaglandin. He had multiple other comorbidities such as congenital pneumonia, anorectal malformations, and glanular hypospadias. FISH test was negative for DiGeorge syndrome. 


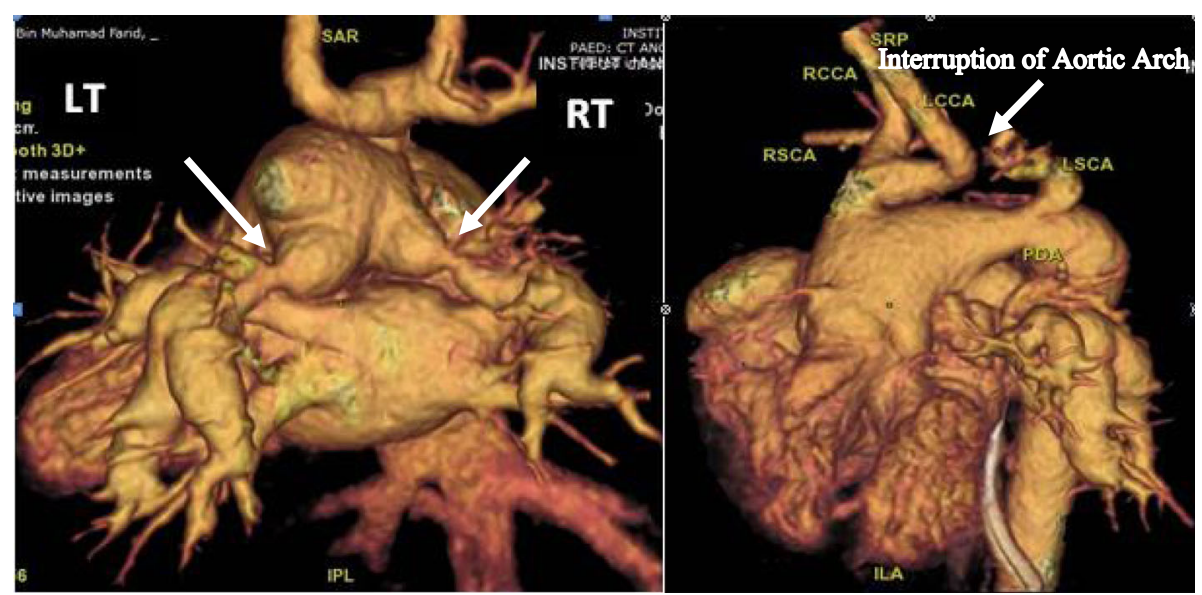

Fig. 1 a Post bilateral PA band. $\mathbf{b}$ IAA type B

In view of low birth weight and multiple co-morbidities, staged repair was planned and bilateral PA banding was done at 11 days of life. A 3-mm polytetrafluorethylene (PTFE) tube was used to create a band and placed on both PAs. The systemic partial pressure of oxygen after PA banding was $44 \mathrm{~mm}$ of mercury with $\mathrm{FiO}_{2}$ of $21 \%$. The patient had good post-operative recovery and was sent to the primary hospital on the fourth post-operative day. Figure 1 demonstrates the computerized tomography (CT) scan of the pulmonary artery after PA banding.

However, the corrective surgery was delayed due to multiple episodes of Klebsiella pneumoniae bacteremia. Immunodeficiency study done revealed deficiency in $\mathrm{T}$ cell line. The PDA was kept patent by intravenous prostin at $5 \mathrm{ng} / \mathrm{kg} / \mathrm{min}$. Following optimization, with a weight of $7 \mathrm{~kg}$, the baby was rendered suitable for definitive surgery after 13 months of PA banding and underwent truncus repair with IAA repair. Cardiopulmonary bypass (CPB) was established using bi-arterial (aortic and PDA) and bicaval cannulation and left heart venting via right superior pulmonary vein. PDA was ligated, and branch PAs were debanded and checked for distensibility. We occluded the branch PAs distal to the debanded site with neurosurgical clips. Ventilation was resumed while partially coming off $\mathrm{CPB}$ to allow the heart to pump against the distally clipped branched pulmonary arteries and allowed them to distend. The branch PAs distended completely without narrowing. $\mathrm{CPB}$ was resumed and pulmonary button was harvested. The arch was reconstructed using autologous pericardium under antegrade cerebral perfusion. Right ventricle to PA continuity was established using a $12-\mathrm{mm}$ Contegra graft. Termination of $\mathrm{CPB}$ was eventful. The chest was closed after $24 \mathrm{~h}$. The patient developed chylothorax, which responded to conservative management and was discharged on the seventh POD. The echocardiography done at the 4th post-operative day showed the gradient across the right PA to be $15 \mathrm{mmHg}$ and through left PA as $20 \mathrm{mmHg}$. On 1 year follow-up, the child was noted to be doing well. The follow-up CT scan showed good branch PAs with no residual stenosis (Fig. 2).

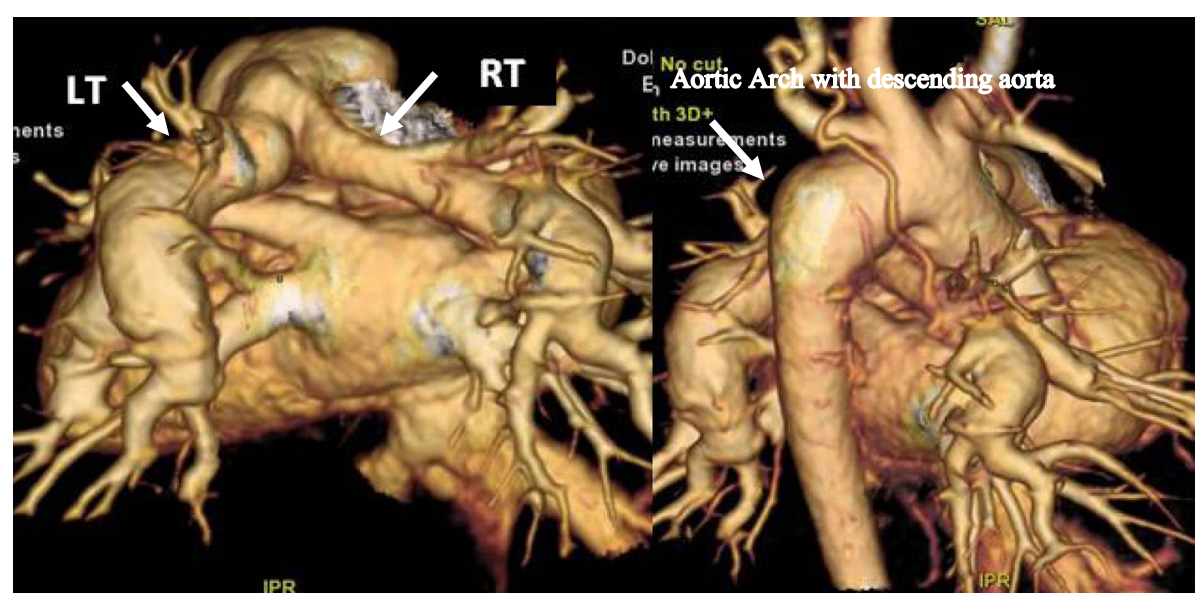

Fig. 2 Post total correction of TA with IAA 


\section{Discussion}

Bilateral PA banding as a staged palliation is predominantly used for single ventricle lesions. However, recent reports have shown that it has become an established palliation for biventricular lesions, especially in truncus arteriosus defect [1]. In view of increased risk of perioperative mortality and reoperation for single-stage repair of complex cardiac lesions in neonates with low birth weight, reports have demonstrated the benefit of bilateral PA band to allow weight gain and maturation of vital organs [2].

The appropriate timing of second stage surgery has been a dilemma as the weight gain post bilateral PA banding was found to have individual variations [1]. Although commonly done at 3 to 6 months post bilateral PA band, the surgery was significantly delayed in our case due to concomitant and ongoing infection pertaining to the immunodeficiency [3]. The major limitation of this procedure remains the possibility of distortion of the branch PA causing stenosis and increasing the need for additional PA plasty [4]. In a case report by Lim et al., when the corrective surgery was delayed for 17 months, the branch PA required repair following debanding [5]. In our case, the corrective surgery although delayed by 13 months did not show narrowing of the branch pulmonary arteries after the release of the PA bands. The use of the PTFE material as a band is reported to minimize the possibility of distortion of the pulmonary arteries as it helps to follow the contour of the banded pulmonary arteries [6].

\section{Conclusion}

Bilateral PA banding serves as an effective palliation in patients with truncus arteriosus with interrupted aortic arch with associated co-morbidities precluding the single-stage surgery. Besides, the use of the PTFE material from a tube graft may help to negate the effects such as stenosis caused by fibrosis as a result of banding for a long period of time.
Funding

None

\section{Availability of data and materials}

Data sharing is not applicable to this article as no datasets were generated or analyzed during the current study.

Ethics approval and consent to participate

It has been included in the manuscript as "Ethical approval from the institutional review board and informed consent was taken from the parents for publishing the case".

\section{Consent for publication}

"Written informed consent for the publication of this data was given by the parent." This statement has also been included in the manuscript.

\section{Competing interests \\ None.}

\section{Author details}

${ }^{1}$ Pediatric and Congenital Heart Centre, National Heart Institute, 145, Jalan Tun Razak, 50400 Kuala Lumpur, Malaysia. ${ }^{2}$ Department of Cardiothoracic

Surgery, National Heart Institute, Kuala Lumpur, Malaysia.

Received: 12 January 2021 Accepted: 19 January 2021

Published online: 30 January 2021

\section{References}

1. Sakurai T, Sakurai H, Yamana K et al (2016) Expectations and limitations after bilateral pulmonary artery banding. Eur J Cardiothorac Surg 50(4):626-631

2. Takabayashi S, Shimpo H, Yokoyama K, Kajimoto M (2007) Truncus arteriosus repair after palliative bilateral pulmonary artery banding. Gen Thorac Cardiovasc Surg 55(1):35-37

3. Miyamoto T, Yoshii T, Inui A, Ozaki S (2013) Staged repair for aortic arch reconstruction and intracardiac repair following bilateral pulmonary artery banding in 3 critical patients. Interact Cardiovasc Thorac Surg 16(6):892-894

4. Davies RR, Radtke WA, Klenk D, Pizarro C (2014) Bilateral pulmonary arterial banding results in an increased need for subsequent pulmonary artery interventions. J Thorac Cardiovasc Surg 147(2):706-712 [cited 2020 Mar 9]. Available from: http://www.ncbi.n/m.nih.gov/pubmed/24280715

5. Lim MH, Sung SC, Kim HT, Choi KH, Lee HD, Kim G (2018) Staged repair of truncus arteriosus associated with complete atrioventricular septal defect. Korean J Thorac Cardiovasc Surg 51(5):356-359

6. Nezafati MH, Nezafati P, Kahrom M (2017) Pulmonary artery banding using polytetrafluoroethylene; Choice of material. ARYA Atheroscler 13(5):202-204

\section{Publisher's Note}

Springer Nature remains neutral with regard to jurisdictional claims in published maps and institutional affiliations.

\section{Submit your manuscript to a SpringerOpen ${ }^{\odot}$ journal and benefit from:}

- Convenient online submission

- Rigorous peer review

- Open access: articles freely available online

High visibility within the field

- Retaining the copyright to your article

Submit your next manuscript at $>$ springeropen.com 